doi: 10.2478/v10221-011-0028-x

\title{
Does the configuration of a primary care system impact on care quality - an exploratory assessment
}

\section{Ali konfiguracija sistema primarnega zdravstva vpliva na kakovost zdravstvene nege (raziskovalna ocena)?}

\author{
Gerrard Abi-Aad ${ }^{1}$, Y-Ling Chi ${ }^{1}$ \\ ${ }^{1}$ Organisation for Economic Co-operation and Development, 2, rue André Pascal, 75775 Paris Cedex 16 \\ e-mail: gerrard.abi-aad@oecd.org
}

pregledni znanstveni članek

UDK: 614.2

članek prispel: 28. 6. 2012; članek sprejet: 16. 7. 2012

citirajte članek kot / cite this article as:

Bilt - Ekon Organ Inform Zdrav 2012; 28(2): 139-150

\begin{abstract}
Primary health care systems (PHCS) can be highly effective at meeting the healthcare needs of people with chronic or multiple morbidity. Under the right conditions it is also the best setting to assess health more generally and to intervene when health risks are identified. For people with an established chronic disease, primary care is also the natural setting to coordinate care and to ensure that patients receive the right balance of specialist vs. generalist input - care that is effectively coordinated can improve the overall quality of care by minimising the need for unnecessary and costly acute care, and by improving patient satisfaction. But how is it possible to measure the configuration of a health system and how do the essential features of health systems relate to quality of care? This paper provides an overview of how this might be approached and discusses the challenges therein.
\end{abstract}

Key words: primary healthcare system, quality, multimorbidity, chronic disease

\section{Izvleček}

Sistemi primarnega zdravstvenega varstva so lahko zelo učinkoviti pri zadovoljevanju zdravstvenih potreb ljudi s kroničnimi ali več sočasnimi boleznimi. Pod pravimi 
pogoji so tudi najboljše okolje za splošno oceno zdravja ter za izvajanje ukrepov, ko prepoznamo tveganja za zdravje. Za ljudi s kroničnimi boleznimi je primarno zdravstvo tudi naravno okolje za usklajevanje nege in zagotavljanje ravnovesja med specialistično in splošno oskrbo. Zdravstvena nega, ki je učinkovito usklajena, lahko izboljša splošno kakovost tako, da stremi $k$ zmanjševanju potreb po nepotrebni in dragi akutni negi ter $k$ izboljšanju zadovoljstva bolnikov. Toda, kako izmeriti konfiguracijo zdravstvenega sistema in ugotoviti, na kakšen način bistvene značilnosti zdravstvenih sistemov odražajo v kakovosti zdravstvene nege? $\checkmark$ prispevku predstavljamo možne pristope in razpravljamo o izzivih, ki se nanašajo nanje.

Ključne besede: sistem primarnega zdravstvenega varstva, kakovost, večkratna obolevnost, kronična bolezen

\section{Introduction}

In many OECD countries, the PHCS is the bedrock of the wider health system, often representing the point of health care contact that patients use the most and are the most familiar with. Furthermore, in the context of rising health care costs, an increase in the prevalence of long term conditions and an increase in the prevalence of multimorbidity, PHCS are now centre-stage in the effort to provide cost-efficient and cost-effective health care.

In the United States, chronic diseases such as coronary heart disease, cancer, and diabetes are the leading causes of death and disability, accounting for $70 \%$ of all deaths. Other research suggests that up to $75 \%$ of health care spending in most developed countries is directly attributable to chronic conditions. The same research suggests that around $30 \%$ of health care expenditure on chronic conditions relates to cardiovascular disease, diabetes and pulmonary diseases. $(1,2)$

Additionally, people's health states are increasingly characterised as comorbid or multimorbid, i.e. having two or more chronic conditions at the same time. Because of the ageing population and changes in people's lifestyle, there are now more patients who fall into this category than ever before. For example, a study based on data extracted from general practice registers in the Netherlands showed that the prevalence of multimorbidity ranged from around $17 \%$ in patients aged $20-39$, to $77 \%$ in patients aged 80 and over. Furthermore, a cross sectional study using general practice data in Scotland, found that there were strong socioeconomic gradients associated with the early onset of multimorbidity, with people living in the most deprived areas experiencing the onset of multimorbidity 10-15 years earlier than people living in more affluent areas. The same study also noted that 'the presence of a mental health disorder increased as the number of physical morbidities increased'. $(3,4)$ 
The deleterious health impacts of multimorbidity are significant, with patients often experiencing worse quality of life, compromised clinical outcomes and complex multi-sectoral health care needs. Because patients with comorbidity or multimorbidity tend to be admitted repeatedly to hospitals and, once admitted, stay for longer and require more intensive treatment and management, the associated costs are often significantly greater than for other, less complex patients. PHCS are ideally situated to manage and coordinate the long-term needs of patients with chronic and multiple occurring diseases, helping to prevent unnecessary deterioration in health/wellbeing. Research has also shown that PHCS are effective settings for preventing illness and death and, in contrast to specialist acute care, are associated with a more equitable distribution of health in populations. $(5,6)$ Moreover, the PHCS often serves as the coordinating hub for specialised care and for the management of chronic conditions. In a number of countries, the PHCS represents the first and most typical point of contact for basic healthcare needs. In the UK for example, of the 300 million patient contacts every year with the National Health Service, ninety per cent take place in a primary care setting. In this regard, the PHCS is naturally situated to provide consistent, coordinated care and to ensure that complex care needs are reviewed and adjusted according to the needs of the patient, as well as contributing to rehabilitation and disease prevention.

In summary, PHCS have a major role to play in promoting health, preventing illness and minimising the deterioration of chronic diseases and multimorbidity. This has the potential to reduce the need for costly and unnecessary hospital care.

Despite this central and crucial role played by PHCS, little attention has been paid to its development. In particular, published research looking at PHCS characteristics and their relation to quality of care are scarce. In this explorative work, we aim to find ways to characterise PHCS and to link their characteristics to the quality of the system. In doing so, we comment on the broad themes that emerge from observations of the way quality varies as salient features of the PHCS change from country to country.

\section{Data}

Indicators used to gauge the quality of PHCS (dependent variable). Measuring the quality of a PHCS is not straightforward. In this study we have used two populationbased indicators to indirectly measure quality:

1. Potentially preventable admissions (PPA) for chronic conditions; and

2. Potential years of life lost (PYLL) for conditions amenable to primary medical care and for cancers amenable to early detection within a primary care or community setting. 
The Health Care Quality Indicators (HCQI) project which is coordinated at the OECD ${ }^{1}$ has developed a suite of indicators to gauge the quality of PHCS. For the purposes of this study, PPAs for diabetes, chronic obstructive pulmonary disease (COPD), asthma, hypertension and congestive cardiac failure were used. The PPA indicators are age and sex standardised to enable cross-country comparisons and the data collection process from countries is regulated by precise extraction criteria in order to minimise data quality issues².

In addition to the PPA indicators, we also compiled PYLL indicators for conditions considered amenable to interventions that are often organised within the PHCS. These conditions fall into two categories - (1) chronic conditions (diabetes, hypertension, COPD, asthma, ischaemic heart disease and congestive cardiac failure) and (2) cancers amenable to early detection (skin, colorectal, cervix, breast and prostate).

The causes of death for chronic conditions and cancers, considered either amenable to treatment in a primary care setting (chronic conditions) or amenable to early detection in a primary care setting (cancers) were shortlisted from two seminal articles. Mortality data were obtained via the WHO Mortality Database, using the ICD-10 mortality tabulation. All deaths under the age of 75 years were assumed to be premature and the resulting PYLL estimates were indirectly age and sex standardised to minimise variations arising from population differences. To account for the differences in distribution between indicators, the PPA and PYLL indicators were normalised using the $z$ score method. $(7,8)$

Indicators used to characterise PHCS (independent variable). The organisation, financing and governance of PHCS differ considerably from one country to another. OECD PHCS were 'characterised' using a suite of health system 'measures' adapted from the literature. The selected measures are shown in Box 1. (9)

These indicators were selected not only because they combine a mix of macrolevel system descriptors that pick up on funding, efficiency and equity, but also because they represent issues that are of concern - access, affordability and choice - to patients. An additional indicator - total national expenditure on health - as a proportion of GDP was used to gauge the overall level of commitment to healthcare provision and thereby health gain more generally.

\footnotetext{
1 For more information describing the HCQI project please follow the link below (http://www.oecd. org/document/34/0,3746,en_2649_37407_37088930_1_1_1_37407,00.html)

2 More information regarding the technical specification for the PPA indicators and the data collection process is available in the document "OECD Health Care Quality Indicators Data Collection for 2010-11"
} 
1. Level of copayment for drugs and for family physician services. (1. High copayment; 2. Medium copayment; 3. Low copayment).

2. Density of family physicians per 100000 population

3. Extent of GP gatekeeping (1. Low gate keeping; 2. Medium gate keeping; 3. High gate keeping)

4. Ability to choose own GP (1. Limited choice; 2 . Incentivised choice; 3. Free choice)

5. Predominant practice structure (1. Solo GP; 2 . Mixed provision of services; 3. Mostly group practice)

6. Total national expenditure on health as a proportion of GDP

Box 1. PHCS descriptive indicators used to perform cluster analysis.

The PHCS characteristic indicators were coded on a three point scale for the purpose of statistical clustering. Indicators 1, 3, 4 and 5 were ordinal and were simply banded to provide uniform trends in terms of their quality enhancing potential. Indicators 2 and 6 , were percentile ranked and cut off points were selected at each tertile point i.e. countries at the lower tertile range were assigned a score of one. Total national expenditure was ranked as 1. Low, 2. Medium and 3. High.

Data for each country were obtained using both the Primary Health Care Activity Monitor for Europe (PHAMEU - a pan European project coordinated by the Netherlands Institute for Health Services Research), and the health systems characteristics project coordinated by the OECD.

\section{Methods}

We used cluster analysis and regression modelling to assess whether PHCS characteristics can be utilised to make sense of health system and quality of care differences and, in doing so, to identify policy messages around health system development ${ }^{3}$.

\section{Cluster Analysis}

Cluster analysis is a statistical process for grouping disparate variables so that the grouped data are similar in certain respects. The average performance of the clusters can be compared to gain insights as to whether the particular features of clusters might explain better (or worse) performance than other clusters.

\footnotetext{
3 The regressions are not discussed in this paper but can be reviewed in a separate OECD document “What Explains Differences in Primary Care?" (DELSA/HEA/HCQ (2011)3) on request.
} 
The clustering is done using a statistical approach technique: countries are not allocated to different categories through expert knowledge, but rather because they can be said to be statistically similar to one another.

Ward's Minimum Variance Method and agglomerative classification was used to form the clusters. Statistical clustering was carried out using the PHCS characteristics shown in Box 1. Total national health expenditures as a share of GDP was also used to indicate overall commitment to health spending as it was not possible to obtain accurate information on health expenditure for PHCS specifically.

\section{Results}

The results of the cluster analysis are presented in Figure 1 below. The Approximate Unbiased (AU) $p$-values generated through multi-scale bootstrap re-sampling, are displayed in the circles in each branch.

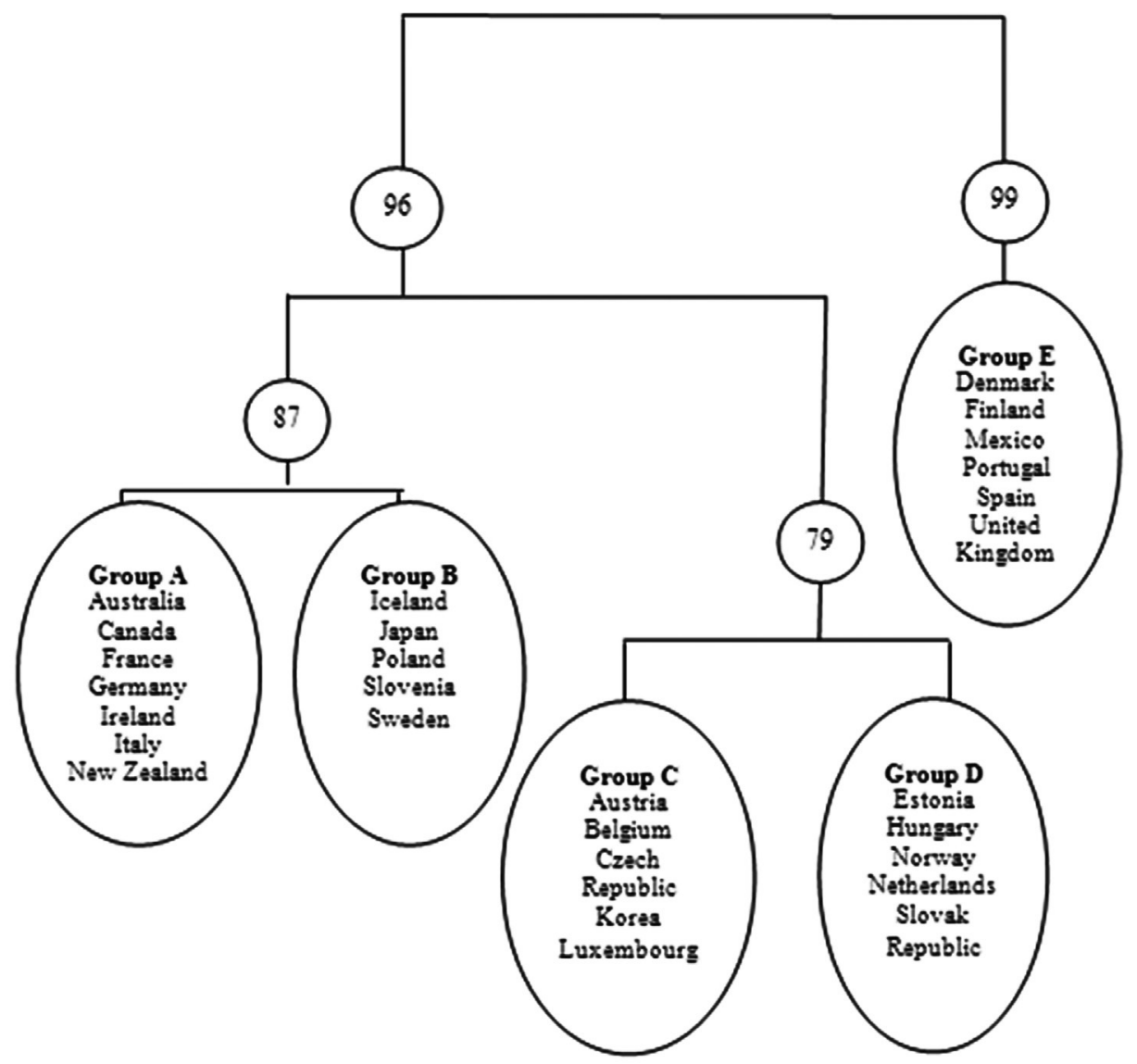

Figure 1. PHCS country statistical clusters (countries were grouped using the independent PHCS characteristics shown in Box 1). 
The confidence level associated with each cluster is high ( $p$ values $>70$ ), especially for Group E which differs significantly from the other cluster groups. The clusters display similarities on the following key features (Table 2):

\section{Group A}

- Countries in Group A have strong PHCS features with medium to high density of family physicians. This group has medium-tolow copayment characteristics and medium-to-high levels of gate keeping. Group A is also characterised by group or mixed practice composition settings.

\section{Group B}

- Group B is characterised by high concentrations of group practices but with low overall family physician density. Patients in group B have high freedom of choice of provider and experience a lowto-medium level of copayment for GP services and prescribed pharmaceuticals. Group B is also characterised by strong gatekeeping.

Group C

- Group C has medium to high family physician density but is characterised by a PHCS composed almost entirely of solo practices. The group also has low gatekeeping, although in general terms patients are free to choose their physicians.

Group D

- Group D exhibits high freedom of choice (patient's ability to choose own GP) and gatekeeping. The PHCS is dominated by solo practices and medium levels of copayment. The density of GPs is also low compared with the other OECD countries.

\section{Group E}

- Group E has low provider choice, high gatekeeping and tends to be typified by group practice settings. Countries are also characterised by the high density of providers. The level of copayment is also typically low/medium.

We looked at the level of variation in primary care quality within and between clusters (i.e. using PPAs and PYLLs as quality markers). In general terms it was noted that quality of care has been improving in recent years, but remains highly 
variable between countries. Despite wide variations in quality of care, some countries consistently stand as outliers ${ }^{4}$, as shown by Figure 2 .

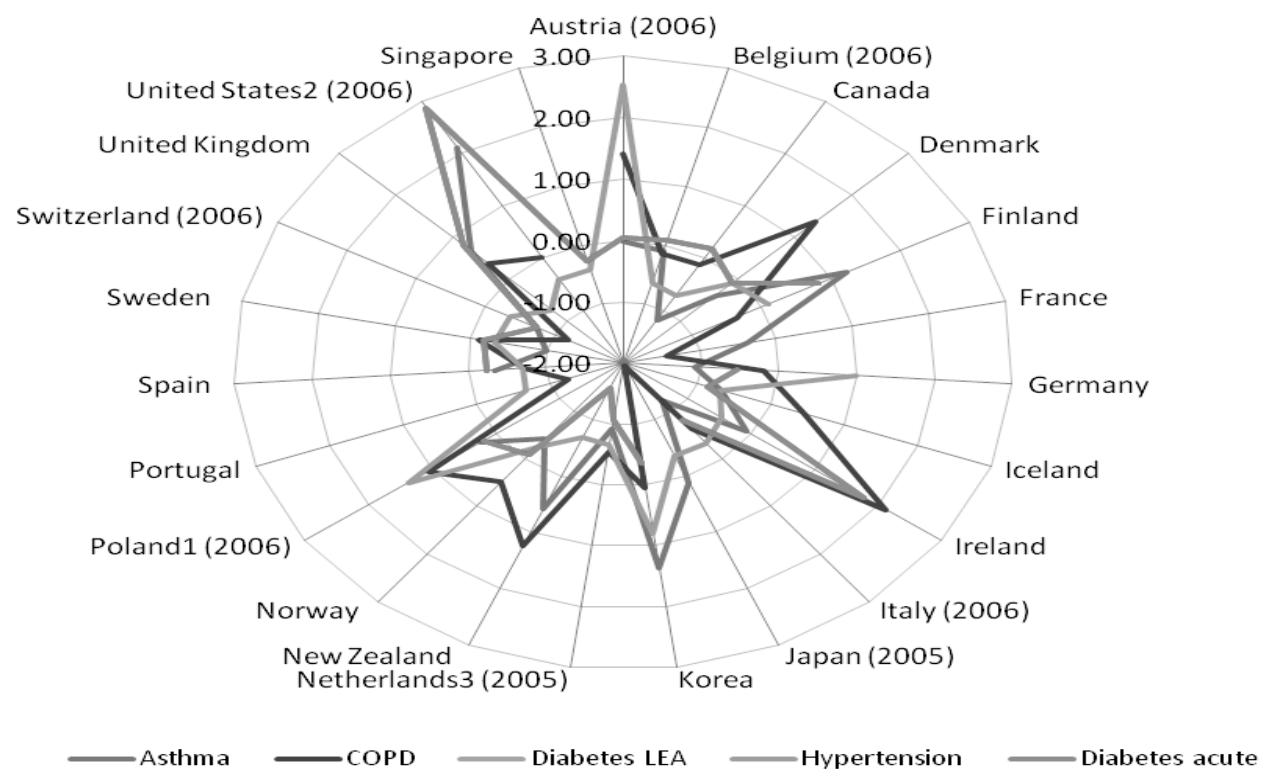

Source: adapted from OECD Health Data, 2010

Figure 2. z-scores for potentially preventable admission rates for asthma and COPD, diabetes and hypertension.

We calculated the median PYLL for each cluster and for all conditions. Clusters were then ranked by their condition-specific median score - the ranks within cluster are shown in Table 1. A rank of 1 equates to the least years of life lost and a rank of 5 equates to the most years of life lost.

Table 1. Summary statistics for clusters.

\begin{tabular}{|llllll|}
\hline & Group A & Group B & Group C & Group D & Group E \\
\hline Breast cancer & 4 & 1 & 2 & 5 & 3 \\
Cervical Cancer & 1 & 2 & 3 & 5 & 4 \\
Prostate Cancer & 2 & 5 & 1 & 4 & 3 \\
Colorectal & 3 & 4 & 1 & 5 & 2 \\
Skin cancer & 2 & 4 & 3 & 5 & 1 \\
Amenable mortality & 2 & 1 & 3 & 5 & 4 \\
\hline
\end{tabular}

\footnotetext{
$4 \mathrm{Nb} 68 \%$ of all z-scores fall within \pm 1 standard deviation of the mean; $95 \%$ of all scores within \pm 2
} standard deviations; and $99.7 \%$ within \pm 3 standard deviations (in a normally-distributed dataset). 
Although the statistical coherence of the clusters appears strong, in general terms when the quality performance of each cluster is considered no real consistent pattern emerges.

Group A tends to perform very well with ranks of 1 and 2 for cervical, prostate and skin cancer, and a rank of 2 for amenable mortality. However, this Group performs less well on breast cancer. Within the cluster, France and Italy tend to report much lower scores for all conditions compared with other countries.

Group $\mathrm{C}$ is ranked the best performer for prostate and colorectal cancer. This score is partly imputed to the presence of a major outlier (Korea), reporting PYLL up to 7 times lower than the rest of the group for prostate cancer.

Group D which is ranked last or second last for all conditions. A number of these countries were also categorised as extreme PYLL outliers. The exceptions in the group are the Netherlands and Norway who have much lower PYLL for amenable mortality than the rest of the group.

\section{Discussion}

Measuring health system performance is an imprecise science. Allowing for missing data, and making sense of the relationship between system characteristics and national-level quality markers, where the number of data points are limited, is problematic. The analysis in this study was hampered to some extent by the quality and consistency of the available system characteristics information.

Nevertheless, it was possible to group countries using six health system indicators. The advantages to this approach result from enhanced comparative capability with homogeneous country clusters, one is better able to compare and interpret quality and performance trends because the variance in quality is not due to differences in the way the health system is configured. This makes it possible not only to compare absolute but also relative (within cluster) differences in quality.

The clusters developed for the almost complete sample of OECD countries had system characteristic coherence, but failed to explain differences in primary outcomes to any significant degree. That said, in the univariate regression models, density of family physicians per 100000 population and total national expenditure on health as a proportion of GDP were both significantly and positively associated with increased quality gains.

These results suggest, tentatively, that resources devoted to primary care appear to have a bigger effect on outcomes than the configuration of services. As total expenditure on health and GP density increase, the years of (premature) life lost due to amenable mortality decrease.

Analysis of the PPA and PYLL measures shows that there are high levels of variation between measures and between countries. Assuming, at least in part, that these measures do provide an indirect assessment of the quality of primary care, it 
would appear that there are significant opportunities for improving the preventive and management aspects of chronic conditions and early detection of certain cancers within the primary care setting. This appears to be particularly the case for Hungary, Estonia, Poland and the Slovak Republic. It is important to emphasise that we cannot necessarily infer from these results that there are causal links between the strength of PHCS, and differences in preventable admissions or years of life lost. However, it is reasonable to assume that the natural setting to host or coordinate the types of preventive or early detection interventions, that are likely to impact positively on these outcomes, would indeed be delivered in primary care settings. This is supported by successful experiences in OECD countries in managing chronic conditions and improving patients' health status. For instance, in Germany, the Disease Management Programme implemented in 2002 heavily supported coordination of care at the level of the referring GP. This programme has already produced considerable gains in quality of care and in standards of living for enrolled patients with chronic conditions, especially for patients with diabetes.

\section{Conclusion}

In this paper, information about the characteristics of health systems have been used to group systems into analytically meaningful clusters. This approach was seen as advantageous because even with the availability of internationally comparable indicators, it is difficult to assess the underlying (system characteristic) causes of variation. Grouping countries into statistically homogeneous clusters, on the basis of characteristics that are known to confer or mediate primary care quality, is proposed as a means to better understand the interaction between the quality of PHCS and the way in which the system is configured.

Systematic qualitative and quantitative information about the organisation of PHCS via the PHAMEU Monitor and the health system characteristics work of the OECD provide a good basis for further analytic work to explore how this information can be best employed to shed light on primary care quality variations.

The failure to find an effect on outcomes beyond the resources devoted to care may reflect data limitations. There are two main possibilities. One is that the ways of characterising PHCS are inadequate. The second is that the measures used to characterise primary care quality are inadequate. Both are surely true to an extent. The health systems characteristics information on primary care has clear inadequacies: a crude measure of financial access; failure to take into account waiting times, etc.

The current suite of Health Care Quality Indicators are limited in their capacity to describe primary quality. A wider raft of more direct primary care measures set alongside a more nuanced understanding of PHCS configurations will enhance the 
opportunity not only to hone in on significant quality failures, but also to better understand their underlying determinants. On the basis of the results from this study, the authors advocate the following recommendations.

1. To collect nationally verifiable PHCS characteristic information from all OECD countries. The focus should be on the collection of a small but highly pertinent set of system descriptors that are known to reflect the attributes of effective primary care. Where possible, priority should be given to those attributes that are likely to be of importance to patients e.g. accessibility, affordability and choice.

2. To explore the potential for an enhanced suite of primary care quality measures. In particular to focus on the development of new measures encompassing: multimorbidity, cost-effective prescribing and polypharmacy, embedding mental health care in the primary care setting, a new suite of PYLL indicators for amenable mortality and cancers amenable to early detection in primary care settings.

3. To explore more fully the utility of statistical clustering and relative benchmarking in the context of health system comparative quality monitoring by using key PHCS attributes.

The opinions expressed in this article are those of the authors alone; not those of the OECD, nor of its Member countries. All errors are the responsibility of the authors.

Also with thanks to Emily Hewlett for editorial input.

\section{References}

1. Murray CJ, Lopez AD. Alternative projections of mortality and disability by cause 1990-2020: Global Burden of Disease Study. Lancet 1997; 349(9064): 1498504.

2. Brandt S, Hartmann J, Hehner S. How to design a successful disease-management program? McKinsley Q 2010; 10: 68-79.

3. Fortin M, Hudon C, Haggerty J, Akker M, Almirall J. Prevalence estimates of multimorbidity: a comparative study of two sources. BMC Health Serv Res 2010; 10(1): 111.

4. Barnett K, Mercer SW, Norbury M, Watt G, Wyke S, Guthrie B.Epidemiology of multi-morbidity and implications for health care, research, and medical education: a cross-sectional study. Lancet 2012; 380(9836): 37-43.

5. Starfield B, Shi L, Macinko J. Contribution of Primary Care to Health Systems and Health. Milbank Q 2005; 83(3): 457-502.

6. Kringos DS, Boerma WG, Hutchinson A, van der Zee J, Groenewegen PP. The breadth of primary care: a systematic literature review of its core dimensions. BMC Health Serv Res 2010; 10: 65.

7. Nolte $E$, McKee M. Measuring the health of nations: Updating an earlier analysis. Health Aff 2008; 27(1): 58-71. 
Abi-Aad G, Chi Y-Ling. Does the configuration of a primary care system impact on care quality ...

8. Simonato L, Ballard T, Bellini P, Winkelmann R. Avoidable mortality in Europe 1955-1994: a plea for prevention. J Epidemiol Community Health 1998; 52(10): 624-30.

9. Macinko J, Starfield B, Shi L. The contribution of primary care systems to health outcomes within the Organization for Economic Cooperation and Development (OECD) Countries, 1970-1998. Health Serv Res 2003; 38(3): 831-65. 